\title{
Synthesis and properties of linear, branched, and cyclic metallacarborane oligomers*
}

\author{
Russell N. Grimes
}

Department of Chemistry, University of Virginia, Charlottesville, VA 22904, USA

\begin{abstract}
A rapidly developing area of organometallic chemistry centers on polynuclear metal coordination compounds having specified, highly symmetric geometries such as squares, triangles, rectangles, or rigid rods. Interest in such molecules arises in part from their unusual, aesthetically appealing structures, and on the possibilities for assembling them into extended systems having useful electronic, optical, magnetic, catalytic, or other properties. Given their characteristic thermal and oxidative stability, chemical versatility, and relatively low-bulk, metallocene-like steric requirements, small metallacarboranes are attractive candidates as building blocks for such structures. Recent work in our laboratory on the controlled substitution and linkage of these clusters has opened the way to some new metallacarborane "designer" chemistry that is described in this article.
\end{abstract}

\section{INTRODUCTION}

The amazing versatility afforded by polyhedral boron clusters has found application in a wide range of areas including medicine, recovery of radioactive metals, catalysis, polymer science, host-guest recognition, supramolecular chemistry, and the synthesis of new materials [1]. Even now, nearly a half century after the discovery of carboranes, the pace of development in this area is increasing as new ways are found to exploit the properties of these remarkable molecules. Two of the most important attributes of carborane and metallacarborane clusters are their stability toward air-oxidation and their ability to withstand a wide variety of organic and organic reagents without destroying the integrity of the cage structure. These qualities have made possible the development, over time, of a very extensive derivative and substitution chemistry that resembles that of organic chemistry and is rivaled by few other inorganic areas.

Supramolecular systems composed of organic or metal-organic building-block units that are connected by strong covalent bonds [2] are of interest because of their potential for creating "designer materials" having tailorable electronic, optical, magnetic, catalytic, or other properties. Metal-containing supramolecular systems are particularly interesting, since the metal centers may function as tunable electrophores or chromophores. Metallacarboranes are a "natural" for this kind of designer chemistry, given their oxidative and thermal stability, and the small systems (six-vertex nido- $\mathrm{MC}_{2} \mathrm{~B}_{3}$ and sevenvertex closo- $\mathrm{MC}_{2} \mathrm{~B}_{4}$ clusters) offer certain additional advantages: (1) they are similar in steric requirement to metallocenes and hence can more easily replace metal-cyclopentadienyl moieties in organometallic systems; (2) the presence of only three or four boron vertices limits the number of possible isomers of $\mathrm{B}$-functionalized derivatives, simplifying the directed synthesis and isolation of specified target compounds; (3) nido- $\mathrm{MC}_{2} \mathrm{~B}_{3}$ cluster anions exhibit reactivity modes that are not found in the

${ }^{*}$ Lecture presented at the XI ${ }^{\text {th }}$ International Meeting on Boron Chemistry (IMEBORON XI), Moscow, Russia, 28 July-2 August 2002. Other presentations are published in this issue, pp. 1157-1355. 
larger systems (e.g., face-to-face carborane fusion and metal sandwich stacking); (4) as will be shown, the special geometry of seven-vertex $\mathrm{MC}_{2} \mathrm{~B}_{4}$ pentagonal pyramidal cages lends itself to the creation of molecular assemblies and grids based on rigid shapes such as squares, rectangles, and triangles. The exploitation of these properties in non-serendipitous directed synthesis is a long-term project that began in our laboratory more than 20 years ago [3], aspects of which are treated in recent reviews [1c,4]. Here, the focus is on the stepwise construction of polynuclear covalently linked assemblies from small metallacarborane building blocks.

\section{TARGET MOLECULES}

Scheme 1 maps routes to boron-substituted derivatives based on $\mathrm{MC}_{2} \mathrm{~B}_{4}$ cluster starting materials (circled), while Chart 1 outlines target macromolecular architectures. Three basic tasks are addressed: (1) synthesis of suitably functionalized monomers; (2) linkage to create soluble, structurally characterizable oligomers whose electronic and other properties can be studied in solution; and (3) development of methods for the construction of giant molecules or extended solids from monomeric or oligomeric precursors. Electrochemical and theoretical investigations of selected systems, discussed below, are under way in collaboration with other laboratories.

$B=B, B H$

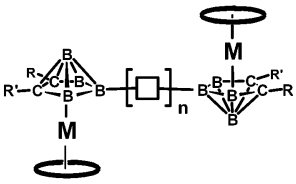

$\mathbf{R}, \mathbf{R}^{\prime}=$ alkyl, aryl, alkenyl, alkynyl

$\rightleftharpoons=$ hydrocarbon ring

$\square=$ linker

$M=$ transition metal
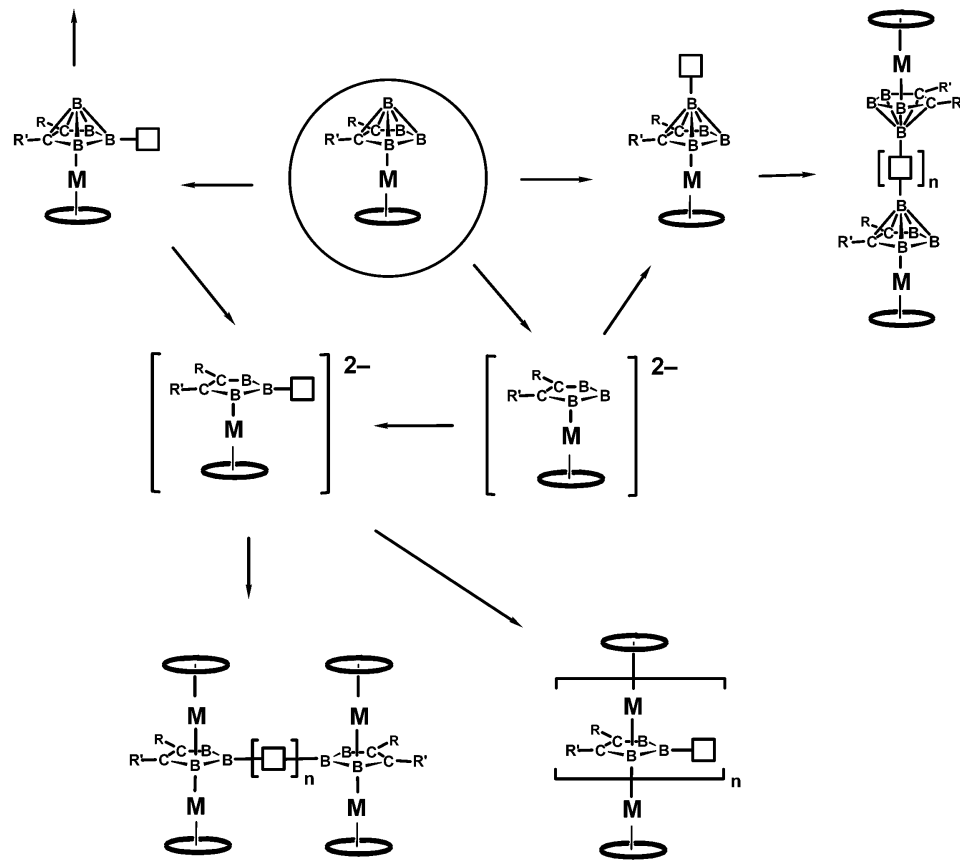

Scheme 1 


\section{Linear Chains}

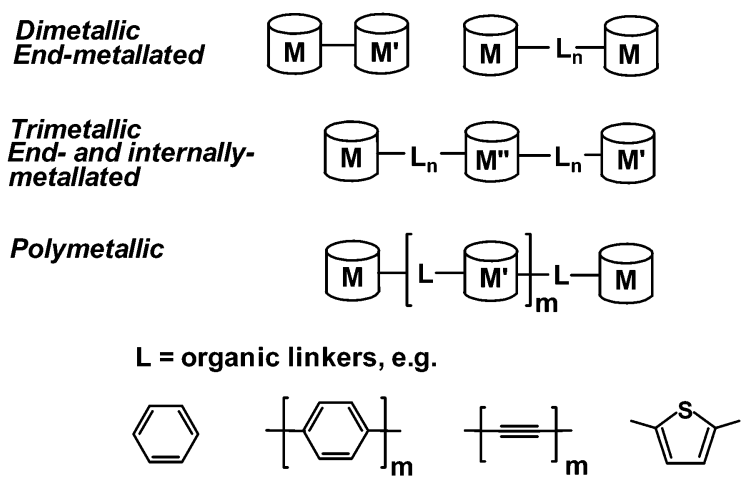

$\mathbb{M}, M^{\prime}, M^{\prime \prime}=$ metallacarborane units,

Trimetallic

End- and internally-

Polymetallic

e.g.,

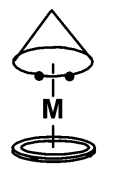

$\mathrm{Cp}{ }^{*} \mathrm{M}\left(\mathrm{R}_{2} \mathrm{C}_{2} \mathrm{~B}_{4} \mathrm{H}_{4}\right)$, (arene) multidecker sandwiches

\section{Branched Chains}

End-metallated

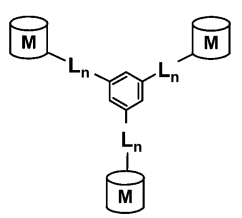

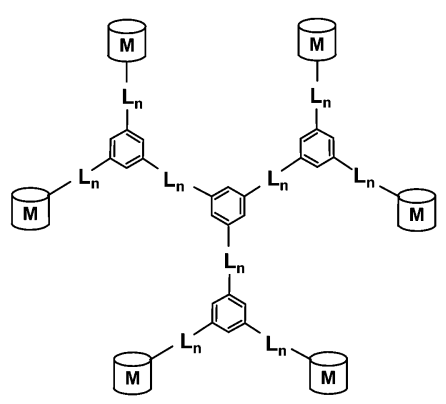

End- and internally metallated<smiles></smiles>

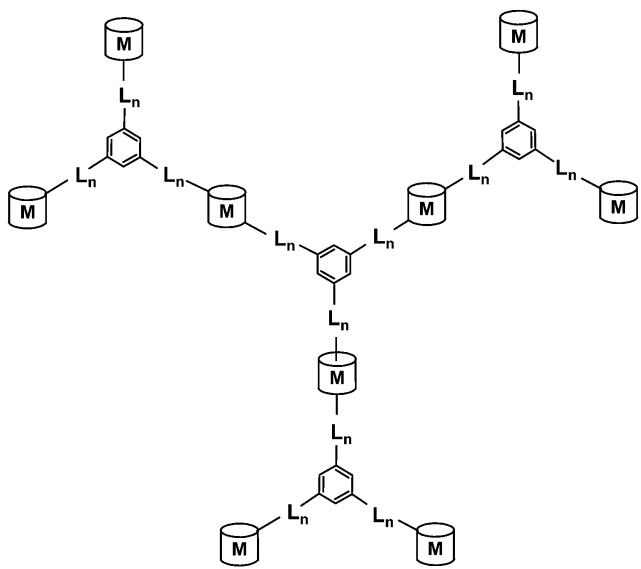

\section{Cycles and Boxes}
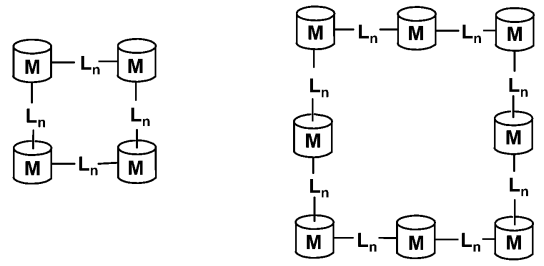
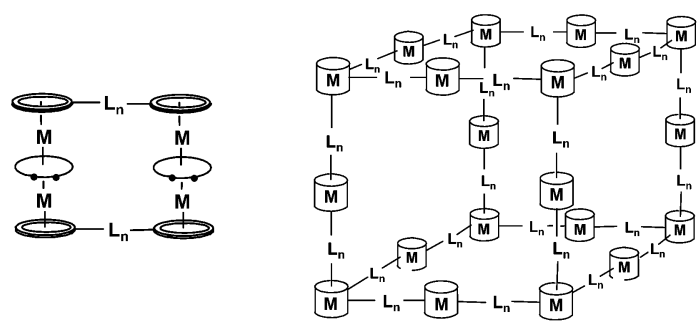

Chart 1 


\section{SYNTHESIS OF B-ALKYNYL BUILDING-BLOCK COMPLEXES}

Small metallacarborane clusters can be linked, either directly or through connecting groups, via bonding to cage boron or carbon atoms, to the metal-bound hydrocarbon ligand (e.g., $\mathrm{Cp}$ or $\mathrm{Cp}^{*}\left[\mathrm{Cp}^{*}=\right.$ $\left.\left.\mathrm{C}_{5} \mathrm{Me}_{5}\right]\right)$, or, rarely, to the metal center [1c,1d,4a,4c]. A variety of organic connectors can be employed, but since a main goal of current research is to prepare polynuclear systems that foster electronic communication between metals, we are primarily interested in phenylene, heterocyclic, and alkynyl linkers that might be expected to serve as electron conduits ("molecular wires"). These and other organic functional groups are introduced at selected boron positions on the cage via strategies that were originally developed for effecting carbon-carbon bonding in organometallic synthesis but have been adapted to carbon-boron bonding for our purposes. Owing to space restrictions, only the alkynyl-derivative chemistry will be discussed in this review.

Our systems employ $\mathrm{LM}\left(\mathrm{Et}_{2} \mathrm{C}_{2} \mathrm{~B}_{4} \mathrm{H}_{3}-\mathrm{X}\right)$ starting materials where $\mathrm{LM}$ is usually (arene)Fe, $\mathrm{Cp} * \mathrm{Co}$, or $\mathrm{CpCo}$, and $\mathrm{X}$ is $\mathrm{Br}$ or $\mathrm{I}$; the halogen is bound at the center equatorial boron [B(5)] or the apical boron $[\mathrm{B}(7)]$. We are exploring two approaches to organosubstitution, namely Negishi-type metalpromoted cross-coupling [5,6] and radical substitution reactions. The latter method is elsewhere [7]; here we concentrate on palladium-catalyzed Negishi coupling [8], which in general is assumed to involve formation of square planar palladium complex intermediates. In an exploratory reaction with trimethylphosphine [5], the Pd complex formed from $\left(\mathrm{C}_{6} \mathrm{H}_{6}\right) \mathrm{Fe}\left(\mathrm{Et}_{2} \mathrm{C}_{2} \mathrm{~B}_{4} \mathrm{H}_{3}-5\right.$-I) underwent B-P elimination to afford a trimethylphosphonium salt (Scheme 2), in contrast to a recent study of Pd-catalyzed cross-coupling in 1,7-C $\mathrm{C}_{2} \mathrm{~B}_{10} \mathrm{H}_{11}$-9-I in which B-I reductive elimination was observed [9].

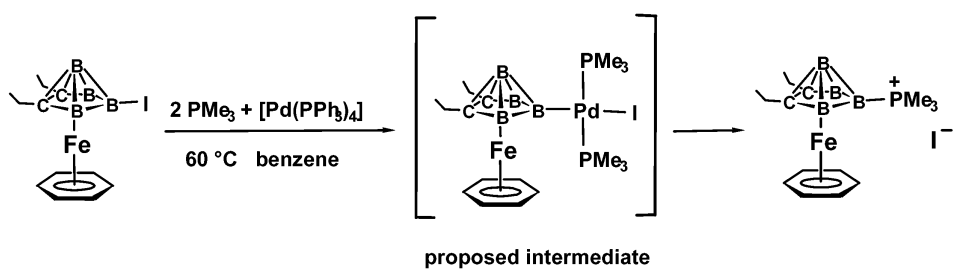

Scheme 2

Scheme 3 illustrates how metal-catalyzed cross-coupling in combination with boron-decapping and boron-insertion reactions have been utilized to generate desired B-mono- and B, $\mathrm{B}^{\prime}$-dialkynyl derivatives, isolated in most cases as brown or yellow air-stable solids [5,6].

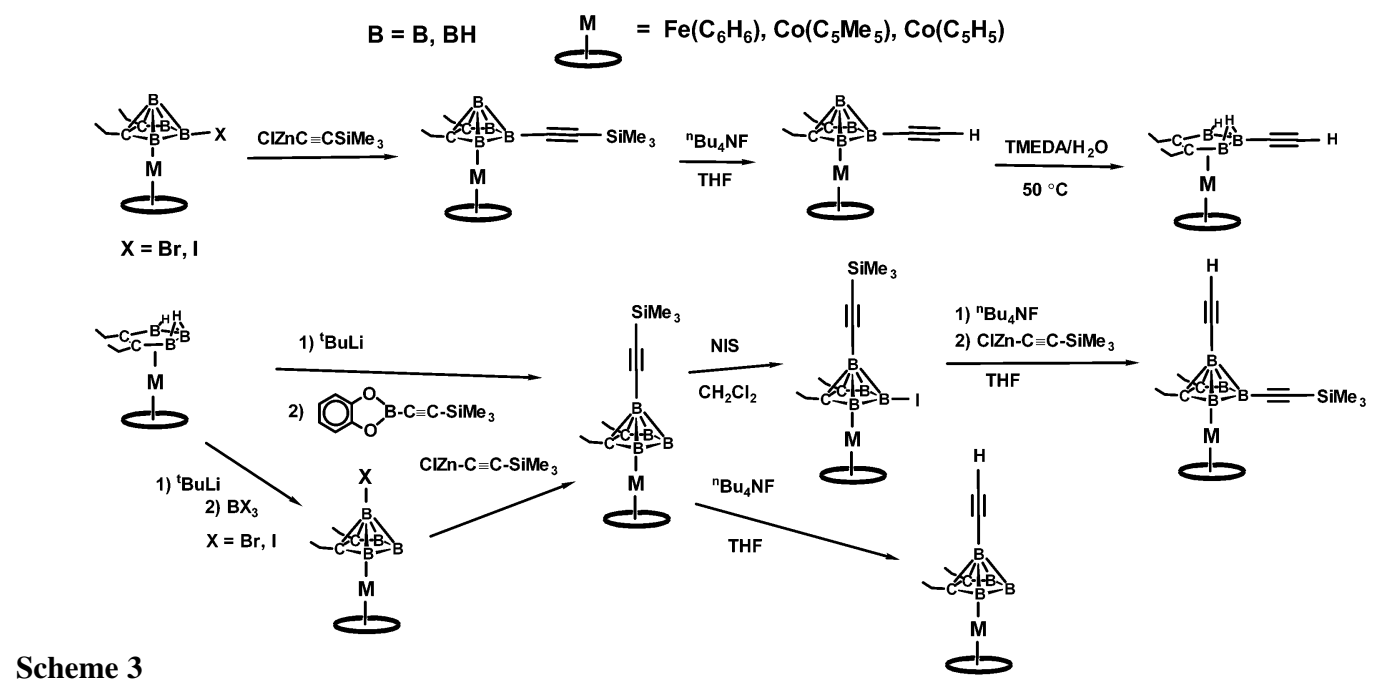

(C) 2003 IUPAC, Pure and Applied Chemistry 75, 1211-1218 


\section{ALKYNE-CONNECTED DINUCLEAR AND POLYNUCLEAR SYSTEMS}

Linkage of basal and apical B-ethynyl substituents to create diacetylenic-bridged complexes $[5,6]$ is illustrated in Scheme 4, while Scheme 5 depicts several examples of benzene-centered polynuclear assemblies; related complexes containing direct benzene-metallacarborane linkages have also been prepared [10]. Trimetallic species of the type shown at the top of Scheme 5, in which the metal-ligand group is $\left(\mathrm{C}_{6} \mathrm{H}_{6}\right) \mathrm{Fe}$ or $\mathrm{Cp} * \mathrm{Co}$, as well as the "triple-triple-decker" system (Scheme 5, right) [11] and the hexakis(cobaltacarboranylalkynyl) assembly (Scheme 5, bottom) in have been synthesized and characterized by multinuclear NMR, IR, and mass spectroscopy, supported in some cases by X-ray crystallography $[5,6,11]$.

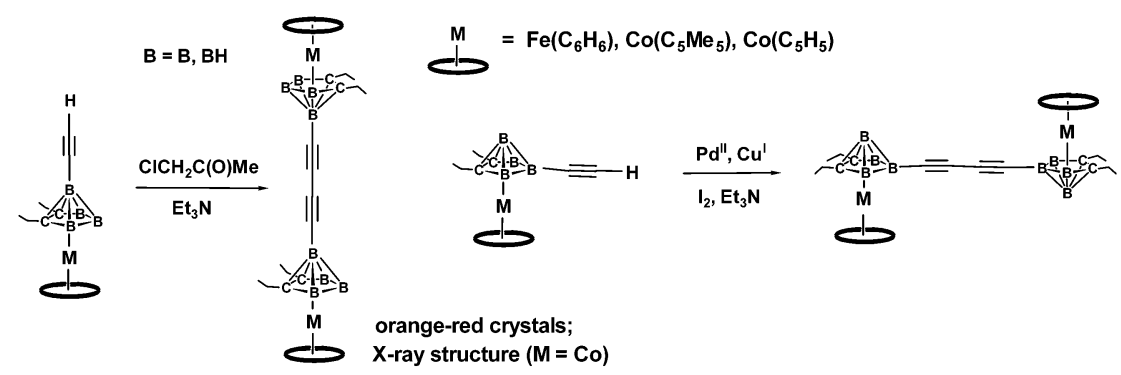

Scheme 4

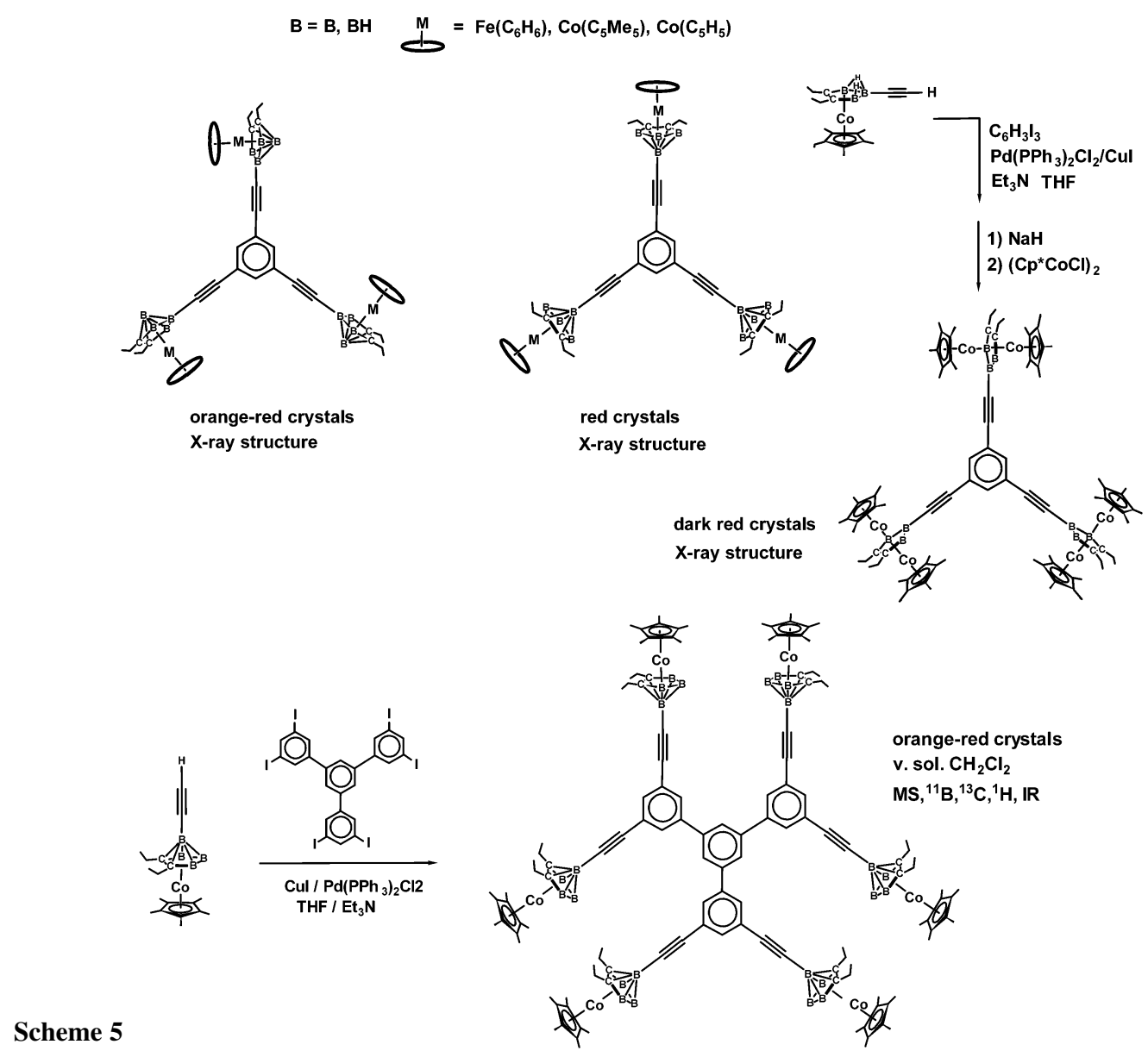

(C) 2003 IUPAC, Pure and Applied Chemistry 75, 1211-1218 
The alkynyl $\mathrm{C} \equiv \mathrm{C}$ bonds can be converted into $\mathrm{Co}_{2} \mathrm{C}_{2}$ cluster units via treatment with dicobalt octacarbonyl as shown in Scheme 6. The proposed hybrid-cluster structures are consistent with spectroscopic data but at this writing have not been crystallographically established [6a].

$B=B, B H$

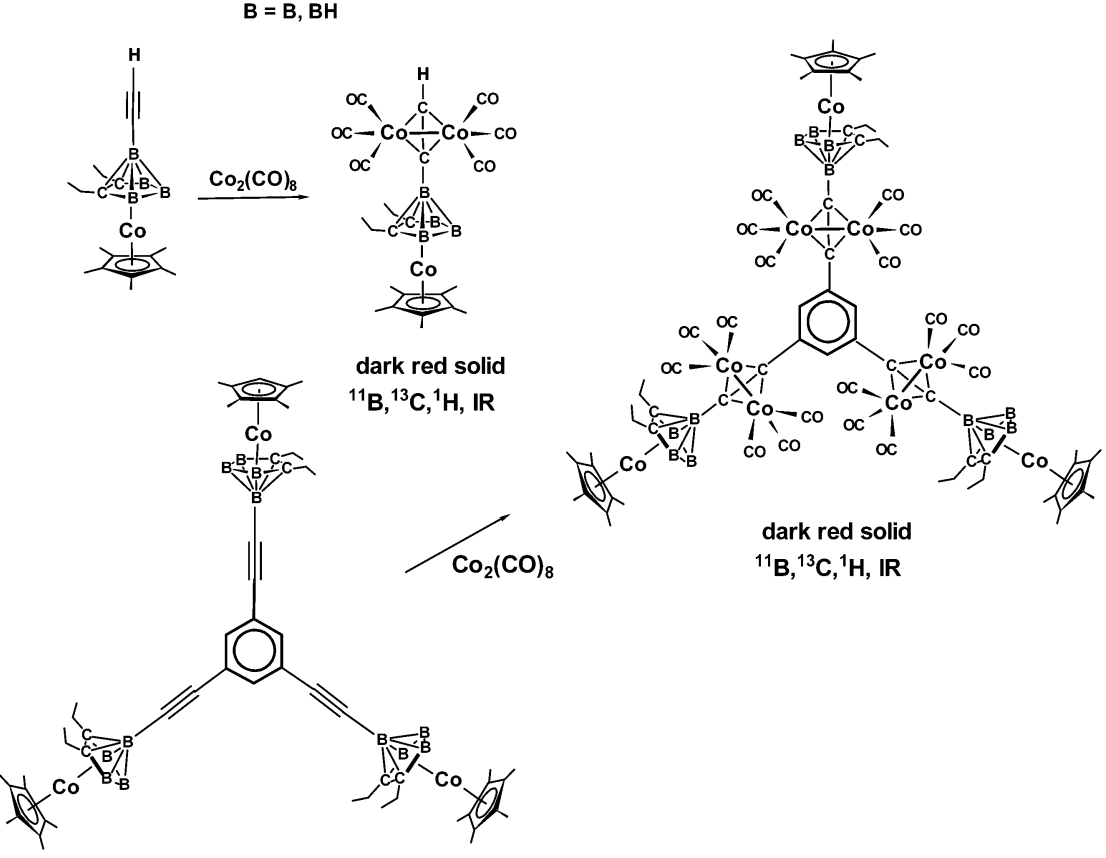

Scheme 6

Small metallacarboranes have a natural propensity to form macrocyclic structures, often as byproducts of polymerization and oligomerization reactions of bifunctional monomers, and in past work our group has been able to isolate and structurally characterize a few such products. These include a rectangular hexametallic cyclic system consisting of two tetradecker sandwiches linked at top and bottom by phenylene rings [12] and a four-cluster, octametallic $\mathrm{Ru}_{4} \mathrm{Co}_{4}$ assembly [13]. However, controlled routes to specified macrocyclic systems have been lacking until now. In very recent work, we have employed metal-catalyzed coupling reactions to assemble a tetranuclear planar octagonal complex [6b] (Scheme 7) and a hexanuclear 3-dimensional diethynyl-bridged structure (Scheme 8) [6c] with reasonable efficiency.

$$
\mathbf{B}=\mathbf{B}, \mathbf{B H}
$$

\section{Scheme 7}

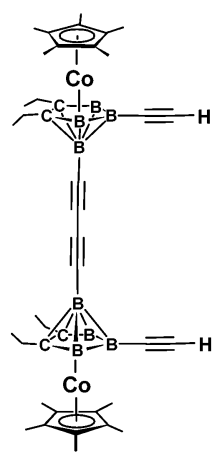

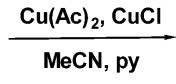

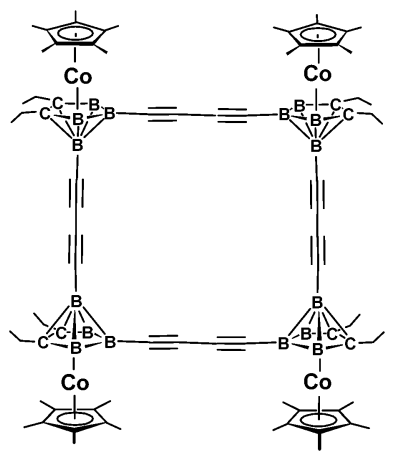

$82 \%$

red-orange crystals

v. sol. pyridine;

part. sol. $\mathrm{CH}_{2} \mathrm{Cl}_{2}$

MS, ${ }^{11} \mathrm{~B},{ }^{13} \mathrm{C},{ }^{1} \mathrm{H}, \mathrm{IR}$ 


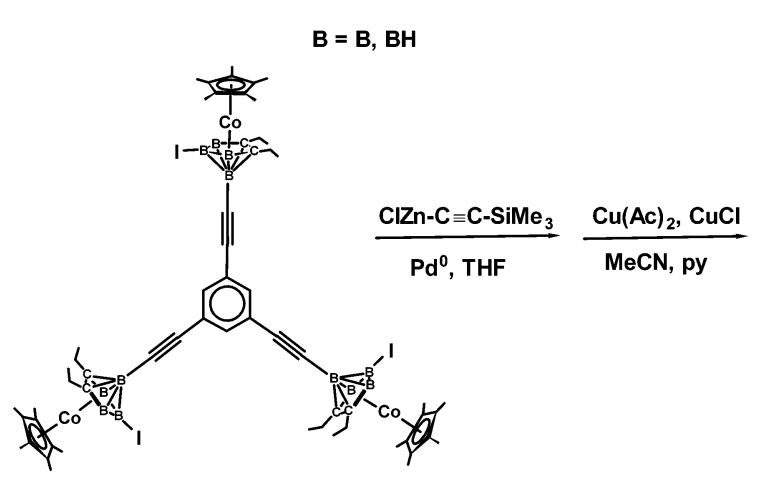

Scheme 8

\section{ELECTRONIC PROPERTIES}

Communication via electron transfer in binuclear and polynuclear small metallacarborane systems encompasses the full range from complete localization (Robin-Day Class I) to full delocalization (Class III), even in seemingly closely related species [14]. Metal-metal electronic interactions are strongly influenced by the choice of metal, metal oxidation state, metal-bound organic ligands, intercage linking groups, cage geometry and substituents, and the position of attachment of connecting groups to the cage. For example, spectroelectrochemical IR studies [14a] reveal that the fulvalenebridged $\mathrm{Co}^{\mathrm{II}}-\mathrm{Co}^{\mathrm{III}}\left(\mathrm{d}^{6} \mathrm{~d}^{7}\right)$ mixed-valence anion $\left[\left(\mathrm{Et}_{2} \mathrm{C}_{2} \mathrm{~B}_{4} \mathrm{H}_{4}\right) \mathrm{Co}\left(\eta^{5}-\mathrm{C}_{5} \mathrm{H}_{4}\right)\right]_{2}^{-}$, an analog of the bicobaltocenium cation, is fully delocalized (Class III) even on the extremely short IR time scale $\left(10^{-13}\right.$ to $10^{-14} \mathrm{sec}$ ), while the corresponding $\mathrm{Co}^{\mathrm{IV}}-\mathrm{Co}^{\mathrm{III}}\left(\mathrm{d}^{5} \mathrm{~d}^{6}\right)$ cation is trapped-valence (Class I). Similarly, fulvalene-connected tetradecker sandwich oligomers show extensive metal-metal communication both between and within the individual stacks, but when the fulvalene connecting ligands are replaced by $\mathrm{C}_{5} \mathrm{Me}_{4}-\mathrm{C}_{6} \mathrm{H}_{4}-\mathrm{C}_{5} \mathrm{Me}_{4}$, ESR and electrochemical evidence indicates that delocalization of the unpaired electron occurs within, but not between, the tetradecker stacks [15].

In (arene) $\mathrm{M}^{\mathrm{III}}\left(\mathrm{Et}_{2} \mathrm{C}_{2} \mathrm{~B}_{4} \mathrm{H}_{4}\right)^{+}$complexes of iron and ruthenium, the $\mathrm{Et}_{2} \mathrm{C}_{2} \mathrm{~B}_{4} \mathrm{H}_{4}{ }^{2-}$ ligand is a strong electron donor to the metal [14c], in contrast to highly unstable organometallic (arene) $\mathrm{M}^{\mathrm{III}}\left(\mathrm{C}_{5} \mathrm{R}_{5}\right)^{2+}$ analogues [16] where $\mathrm{R}=\mathrm{H}$ or Me. (Arene) $\mathrm{M}^{\mathrm{I}}\left(\mathrm{Et}_{2} \mathrm{C}_{2} \mathrm{~B}_{4} \mathrm{H}_{4}\right)^{-}$monoanions, on the other hand, are destabilized by the carborane ligand, but are sufficiently persistent to allow characterization by ESR spectroscopy. In all cases studied, the evidence suggests that the singly occupied molecular orbitals (SOMOs) in these complexes are similar to those of (arene) $M\left(C_{5} R_{5}\right)$ systems.

An electrochemical/theoretical investigation of the alkyne-linked complexes discussed in this article, and of structurally related arene- and heterocycle-connected systems, is under way in collaboration with P. Zanello and co-workers at the University of Siena [14f,17]. In general, we find that compounds incorporating $\mathrm{Fe}\left(\eta^{6}\right.$-arene) groups are less delocalized than are structurally analogous species featuring isoelectronic $\mathrm{CoCp} *$ units. This finding is paralleled by the fact that the cobalt complexes tend to be more stable toward air and other oxidants; the electron-releasing $\mathrm{C}_{5} \mathrm{Me}_{5}$ ligand renders the cobalt clusters more electron-rich than their $\mathrm{Fe}$ (arene) counterparts (as expected, the CoCp complexes are less stable than their CoCp* analogues). In the iron systems, the lower electron density in the vicinity of the metal centers is used primarily in localized metal-ligand binding rather than being delocalized into the cluster framework.

Several of the complexes depicted here command unusual interest as candidates for mixed-valence behavior, e.g., the electrically neutral triple-triple-decker compound in Scheme 5. Oxidation of some of its six identical $\mathrm{Co}^{\mathrm{III}}$ centers to $\mathrm{Co}^{\mathrm{IV}}$, or reduction to $\mathrm{Co}^{\mathrm{II}}$, creates mixed-valence systems that 
have been examined electrochemically [11]. It is found that reduction to the trianion produces three fully electron-delocalized $\mathrm{Co}^{\mathrm{II}} \mathrm{Co}^{\mathrm{III}}$ triple-decker units $(1.2 \mathrm{~V})$, with weak but detectable inter-sandwich communication (ca. $90 \mathrm{mV}$ ). Other evidence of electronic communication is afforded by the UV-visible and ${ }^{1} \mathrm{H}$ NMR spectra [11].

\section{REFERENCES}

1. (a) J. Plesek. Chem. Rev. 92, 269 (1992); (b) Contemporary Boron Chemistry, M. G. Davidson, A. K. Hughes, T. B. Marder, K. Wade (Eds.), Royal Society of Chemistry, Cambridge, UK (2000); (c) R. N. Grimes. Collect. Czech. Chem. Commun. 67, 728 (2002); (d) R. N. Grimes. Coord. Chem. Rev. 200-202, 773-811 (2000).

2. Recent reviews: (a) M. H. Keefe, K. D. Benkstein, J. T. Hupp. Coord. Chem. Rev. 205, 201-228 (2000); (b) M. Fijita and K. Ogura. Coord. Chem. Rev. 148, 249-264 (1996); (c) P. J. Stang and B. Olenyuk. Acc. Chem. Res. 30, 502-518 (1997); (d) S. Leininger, B. Olenyuk, P. J. Stang. Chem. Rev. 100, 853-907 (2000).

3. For a review of early work in this area, see: R. N. Grimes. Pure Appl. Chem. 59, 847-856 (1987).

4. (a) R. N. Grimes. J. Organomet. Chem. 581, 1 (1999); (b) N. S. Hosmane. J. Organomet. Chem. 581, 13 (1999); (c) R. N. Grimes. Applied Organometal. Chem. 10, 209-225 (1996).

5. J. M. Russell, M. Sabat, R. N. Grimes. Organometallics 21, 4113 (2002).

6. (a) H. Yao, M. Sabat, R. N. Grimes, P. Zanello, F. Fabrizi di Biani. Organometallics 22, 2581 (2003); (b) H. Yao, M. Sabat, R. N. Grimes, F. Fabrizi di Biani, P. Zanello. Angew. Chem. Int. Ed. 42, 1002 (2003); (c) H. Yao and R. N. Grimes. J. Organomet. Chem. In press.

7. J. M. Russell, M. Sabat, R. N. Grimes. Organometallics 21, 5613 (2002).

8. E.-I. Negishi. In Metal-Catalyzed Cross-Coupling Reactions F. Diederich and P. J. Stang, (Eds.), Chap. 1, Wiley-VCH, New York (1998).

9. W. J. Marshall, R. J. Young, Jr., V. V. Grushin. Organometallics 20, 523 (2001).

10. M. Bluhm, H. Pritzkow, W. Siebert, R. N. Grimes. Angew. Chem., Int. Ed. 39, 4562 (2000).

11. H. Yao, M. Sabat, R. N. Grimes. Organometallics 21, 2833 (2002).

12. X. Meng, M. Sabat, R. N. Grimes. J. Am. Chem. Soc. 115, 6143 (1993).

13. K. G. Parker, J. M. Russell, M. Sabat, R. N. Grimes. Collect. Czech. Chem. Commun. 64, 819 (1999).

14. (a) T. T. Chin, R. N. Grimes, W. E. Geiger. Inorg. Chem. 38, 93 (1999); (b) T. T. Chin, S. R. Lovelace, W. E. Geiger, C. M. Davis, R. N. Grimes. J. Am. Chem. Soc. 116, 9359 (1994); (c) J. M. Merkert, W. E. Geiger, M. D. Attwood, R. N. Grimes, Organometallics 10, 3545 (1991); (d) J. Merkert, J. H. Davis, Jr., W. E. Geiger, R. N. Grimes. J. Am. Chem. Soc. 114, 9846 (1992); (e) M. Stephan, J. Hauss, U. Zenneck, W. Siebert, R. N. Grimes. Inorg. Chem. 33, 4211 (1994); (f) F. Fabrizi di Biani, M. Fontani, E. Ruiz, P. Zanello, J. M. Russell, R. N. Grimes. Organometallics 21, 4129 (2002).

15. J. R. Pipal and R. N. Grimes. Organometallics 12, 4459 (1993).

16. (a) A. N. Nesmeyanov, N. A.Vol'kenau, E. I. Sirotkina, V. V. Deryabin. Dokl. Akad. Nauk SSSR 177, 1170 (Eng.)/1110 (Russ.) (1967); (b) W. H. Morrison, Jr., E. Y. Ho, D. N. Hendrickson. J. Am. Chem. Soc. 96, 3603 (1974); (c) D. Astruc. Tetrahedron 39, 4027 (1983).

17. F. Fabrizi di Biani, P. Zanello, J. M. Russell, H. Yao, R. N. Grimes. To be published. 